\title{
MIDAS
}

Museus e estudos interdisciplinares

$9 \mid 2018$

Varia

\section{Breve reflexão sobre o património artístico da Faculdade de Medicina da Universidade de Lisboa}

Brief reflection about the artistic heritage of the Faculty of Medicine of the

University of Lisbon

\section{Ana Mehnert Pascoal}

\section{OpenEdition}

\section{Journals}

\section{Edição electrónica}

URL: http://journals.openedition.org/midas/1394

DOI: $10.4000 /$ midas. 1394

ISSN: 2182-9543

\section{Editora:}

Alice Semedo, Paulo Simões Rodrigues, Pedro Casaleiro, Raquel Henriques da Silva, Ana Carvalho

\section{Refêrencia eletrónica}

Ana Mehnert Pascoal, « Breve reflexão sobre o património artístico da Faculdade de Medicina da Universidade de Lisboa », MIDAS [Online], 9 | 2018, posto online no dia 25 janeiro 2018, consultado no dia 01 maio 2019. URL : http://journals.openedition.org/midas/1394 ; DOI : 10.4000/midas.1394

Este documento foi criado de forma automática no dia 1 Maio 2019.

\section{c) (i) (2)}

Midas is licensed under a Creative Commons Attribution-NonCommercial-ShareAlike 3.0 International License 


\section{Breve reflexão sobre o património artístico da Faculdade de Medicina da Universidade de Lisboa}

Brief reflection about the artistic heritage of the Faculty of Medicine of the

University of Lisbon

Ana Mehnert Pascoal

\section{NOTA DO EDITOR}

Artigo recebido a 23.06.2017

Aprovado para publicação a 12.01.2018

\section{Património artístico em ambiente universitário: breve panorama}

1 As universidades são repositórios, muitas vezes centenários, de um património inigualável. Gerado primordialmente em contexto de ensino e de investigação, o património cultural das universidades abarca múltiplas áreas científicas - da Geografia à Matemática, das diversas Engenharias ao Design, englobando variadas tipologias de objetos e de coleções (Lourenço 2005). Este património nem sempre se encontra acessível ou organizado, embora se tenha assistido, nos últimos anos, a um crescente interesse e valorização. Muitas universidades detêm, inclusive, museus destacados no seio da comunidade em que se inserem.

2 O caso específico do património artístico em ambiente universitário apresenta várias realidades. Do ensino nas academias de Belas-Artes, remanescem coleções que incorporam réplicas em gesso (moulages) de grandes marcos da escultura europeia, como é o caso da coleção da Freie Universität de Berlim, que remonta a 1695'1, ou do espólio da 
Faculdade de Belas-Artes da Universidade de Lisboa, cujos exemplares mais antigos datam do séc. XVIII (Bernardo 2014). As obras artísticas geradas em contexto de ensino por alunos e professores, sobretudo provas, tendem a ser preservadas pelas faculdades, constituindo coleções relevantes. Refira-se que estas coleções não são exclusivas das escolas de belas-artes, as faculdades de ciências e de engenharias também conservam espólios de desenhos técnicos e científicos. A Universidade de Montpellier (França), por exemplo, possui um conjunto de 900 aguarelas de botânica de Toussaint François NodeVéran (1773-1852) ${ }^{2}$. Em Portugal, destacam-se a coleções preservadas pelo Museu Nacional de História Natural e da Ciência da Universidade de Lisboa (MUHNAC) ${ }^{3}$ e pelo Museu do Instituto Superior de Engenharia do Porto (MISEP) ${ }^{4}$, ambas com desenhos dos séculos XIX e XX. Aos casos ligados à atividade pedagógica, acrescem museus artísticos em contexto universitário, decorrentes de doações. Comuns nos Estados Unidos, a sua importância extravasa a própria universidade de tutela (e.g. Harvard Art Museums, Eskenazi Museum of Art - Universidade de Indiana). Com maior incidência em campi constituídos ao longo do século XX, refira-se também a existência de obras de arte sitespecific, como scultpture gardens, mas também a decoração artística integrada nos edifícios (não exclusiva do século transato). Finalmente, as universidades têm demonstrado uma apetência por congregar obras artísticas com marcado cunho memorial, como galerias de retratos ou obras que fixam momentos marcantes da sua história.

3 A memória institucional tem sido, ao longo da existência das universidades, uma componente forte e marcante. Estas instituições compreenderam, desde cedo, a importância da preservação da memória das suas origens, dos seus fundadores e antecessores. O peso da ancestralidade foi utilizado como forma de legitimação e validação da sua conduta e tem contribuído para a construção de uma identidade coletiva. Adicionalmente, a preservação de património com cunho memorial, fixando figuras notáveis, como docentes, diretores, reitores, cientistas, alunos, entre outros, ou focando datas marcantes para a instituição, e que possui uma vincada carga afetiva, transmite em simultâneo uma mensagem de estabilidade e de demarcação da hierarquia (Felismino 2016). Neste sentido, grande parte das universidades preserva galerias de retratos, pintados ou esculpidos, que se inserem nesta linha evocativa e identitária. A Universidade de Uppsala (1477), na Suécia, possui uma considerável coleção de arte, reunida desde o século XVII com o propósito principal de manifestar a história da instituição através de uma série de retratos pintados, atualmente alojados em vários espaços no seu edifício principal (1887)5. Outro caso digno de menção é o da Universidade de Sevilha (Espanha), com origem no Colegio de Santa Maria de Jesus (1505); esta instituição detém um considerável espólio composto por diversas coleções de retratos pintados de reitores, professores, monarcas, chefes de estado, e também de sevilhanos ilustres, reunindo mais de 150 obras individuais, sobretudo dos séculos XIX e XX, em várias das suas faculdades ${ }^{6}$. No edifício principal da Universidade de Viena (Áustria), inaugurado em 1884 , saliente-se o Arkadengang, um dos seus pontos centrais. Sob esta arcada com $70 \mathrm{~m}$ de comprimento estão alojados diversos bustos, baixos-relevos e placas comemorativas alusivas a figuras destacadas da instituição. ${ }^{7}$ No panorama português, recorde-se a Sala dos Capelos, no Paço das Escolas da Universidade de Coimbra, cuja função - a realização de cerimónias e provas académicas - é enaltecida pela dimensão solene conferida pelos retratos a óleo dos monarcas portugueses expostos nas paredes. ${ }^{8}$ Mais recentemente, mencione-se o empreendimento da Faculdade de Letras da Universidade de Lisboa, que, após a inauguração do seu edifício em 1958, encomendou cinco bustos em bronze representando 
alguns dos seus mais notáveis docentes, ainda hoje colocados nos passos perdidos (Pascoal 2012).

4 O edifício da Escola Médico-Cirúrgica de Lisboa $(1906)^{9}$, precursora da atual Faculdade de Medicina da Universidade de Lisboa e da qual proveio a grande maioria do seu património artístico, inseriu-se num espírito oitocentista de construção (e readaptação) de escolas superiores ocorrido em diversos pontos europeus. ${ }^{10}$ Autênticos palacetes e templos de saber, adequados às correntes arquitetónicas em voga, surgiram edifícios (e.g. Escola de Farmácia de Paris, 1882) com a preocupação de que a decoração - não só ao nível interior, mas também nas fachadas - espelhasse os valores do conhecimento e do ensino, com recurso primordial a cenas históricas, alegorias, e «metonímias e antonomásias visuais» (Afonso 2013, 315).

\section{O património artístico da Faculdade de Medicina da Universidade de Lisboa: contributos para uma leitura}

5 A Faculdade de Medicina da Universidade de Lisboa encontra-se a funcionar, desde meados da década de 1950, no edifício construído para o Hospital Escolar de Santa Maria, uma obra do arquiteto Hermann Distel (1875-1945). Integrado no complexo da Cidade Universitária de Lisboa, este foi o primeiro edifício construído de raiz a ser inaugurado nessa área da cidade, dando início à concretização de necessidades sentidas há várias décadas (Pascoal 2012; Pascoal 2017). A Faculdade ocupa parte desse edifício de grandes dimensões ${ }^{11}$ (com espaço entretanto ampliado através do Edifício Egas Moniz, em 2004), cujas preocupações de assistência e funcionalismo se sobrepuseram a qualquer intento de decoração artística ${ }^{12}$. A Faculdade de Medicina da Universidade do Porto inaugurou, em 1959, um edifício de modelo idêntico, embora de menores dimensões - o Hospital de São João - que, contrariando o exemplo lisboeta, foi dotado de um programa artístico decorativo concebido de raiz, à imagem do que comummente se realizava para edifícios públicos nesse período. ${ }^{13}$

6 Aquando da transferência do edifício no Campo Santana para as novas instalações, em $1956^{14}$, a Faculdade levou consigo um conjunto de obras de arte móveis. ${ }^{15}$ A perpetuação da memória e da história da Escola, a homenagem das figuras a esta ligadas ao longo dos tempos, bem como o avultado investimento feito no edifício simbolicamente inaugurado em $1906^{16}$ - incluindo pintura mural dos espaços por Veloso Salgado, José Malhoa ou António Ramalho, azulejos de Jorge Colaço, um busto da autoria de Teixeira Lopes, entre outros ${ }^{17}$ (Pina 2007), que permaneceram no edifício - terão sido os principais fatores dessa decisão. A transferência fez perdurar a ligação às raízes da instituição, enaltecendo atores e acontecimentos decisivos do seu passado. Muitas peças detêm, além do seu intrínseco valor histórico (que, por vezes, transcende os limites da Escola ou da Universidade) e artístico, uma vincada carga simbólica e memorial.

7 Do conjunto transferido, as pinturas sobre tela constituem o núcleo de maior expressão. Destaca-se o conjunto de quatro pinturas a óleo, de grandes dimensões, da autoria de Columbano Bordalo Pinheiro (1857-1929). Concebidas para a Sala do Conselho da Escola Médico-Cirúrgica entre 1906 e 1907, estas pinturas retratam 19 professores notáveis da denominada "Geração de 1911" (Costa 2000), figuras de relevo na reforma da Medicina que ocorria no país, e que então exerciam funções. ${ }^{18}$ Trata-se de composições sóbrias, de fundos despojados de tonalidades escuras, com os retratados em primeiro plano (Freitas 
1999). Alguns apresentam-se acompanhados de livros (ao invés dos instrumentos que os poderiam caracterizar enquanto médicos), símbolos de erudição e cultura; cada figura é perfeitamente identificável, prestando-se ao intento da escola em fixar este decisivo grupo. Pouco após a transferência para as novas instalações, a Faculdade demonstrou preocupação na preservação destas telas, como se comprova através de um pedido de beneficiação às oficinas estatais em $1956 .{ }^{19}$

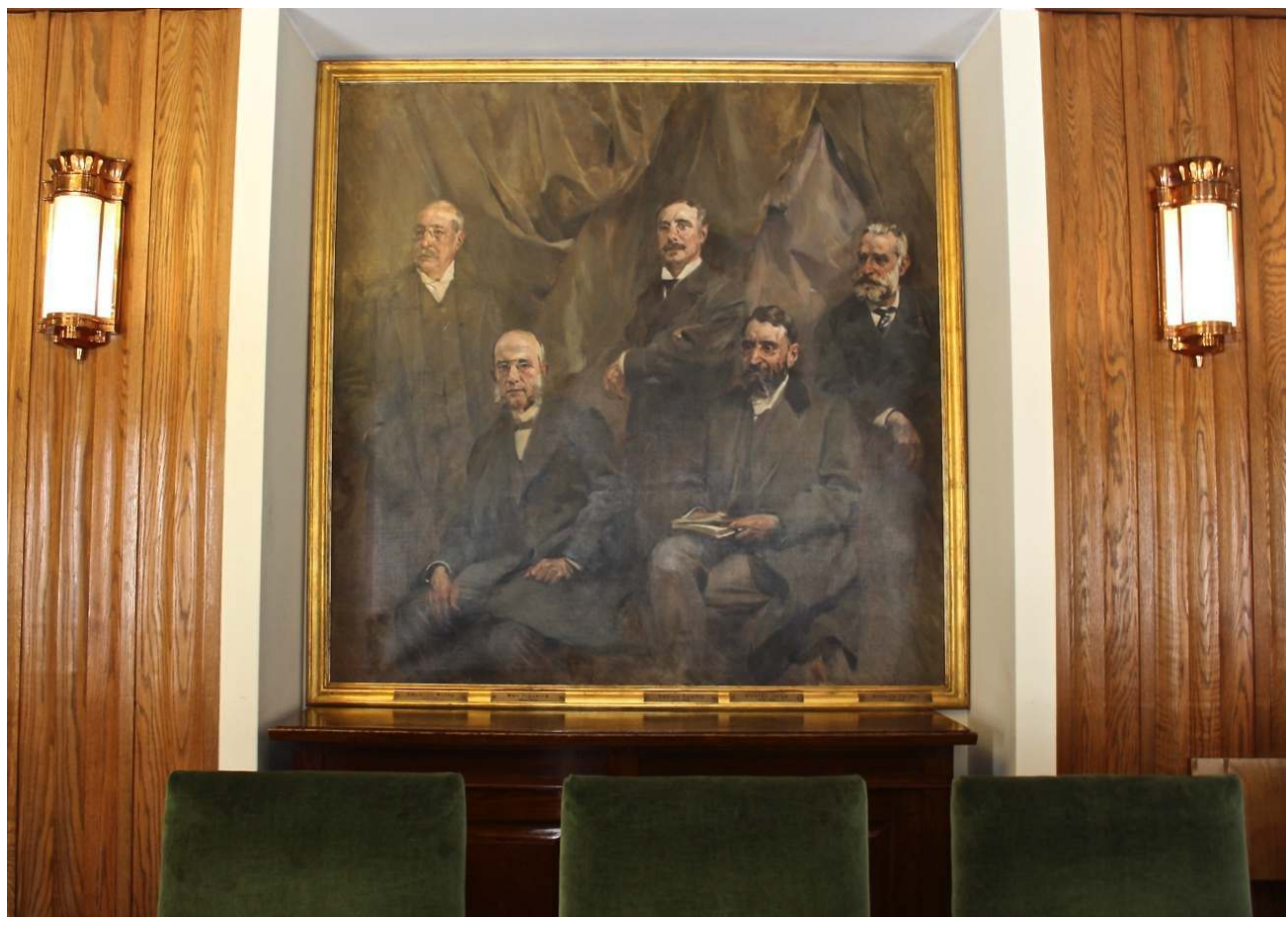

Fig. 1 - Pintura da autoria de Columbano Bordalo Pinheiro, retratando professores de Medicina, 1907 Fotografia da autora, cortesia da Faculdade de Medicina da Universidade de Lisboa

Das antigas instalações transitou outro núcleo de pintura, mais heterogéneo em termos de expressão plástica, originalmente localizado nos gabinetes do Diretor e do Secretário. Segundo Sacadura e Machado (1965), estas pinturas serão provenientes do período em que a Escola Médico-Cirúrgica funcionou num anexo do Hospital de São José (1836-1911). Integra dez retratos de médicos e professores oitocentistas da instituição. ${ }^{20} \mathrm{~A}$ maioria foi representada envergando traje académico. Acresce um retrato pintado por Varela Aldemira (1895-1975) em 1925, representando Manuel Constâncio (1725-1817), cirurgião da Real Câmara, apresentando o seu tratado de Anatomia. Trata-se de uma cópia de um original, de data desconhecida, que se encontraria na Quinta do Vale da Louza ${ }^{21}$, com autoria atribuída a Manuel da Costa (Oliveira 2013), possivelmente mantida num ímpeto de rememoração das origens e evolução da disciplina em Portugal.

A transferência de obras de arte do antigo edifício incluiu também elementos integrados na arquitetura ${ }^{22}$. É o caso de 12 medalhões esculpidos em mármore, da autoria de José Moreira Rato (1860-1937), que se encontravam nas fachadas. Representam mestres portugueses e estrangeiros de grande mérito, com atividade pedagógica iniciada antes de 1836 (i.e., antes do estabelecimento da Escola Médico-Cirúrgica) ${ }^{23}$, correspondendo à lista apresentada por José António Serrano ao conselho escolar em dezembro de 1900. O funcionamento quase cinquentenário no Campo Santana, e a transição para um edifício sem planos concertados de decoração, explicam esta atitude. Os medalhões ornamentam espaços nobres da Faculdade desde 1995, após um processo iniciado em 1989 por João 
Frada, que culminou na identificação da totalidade do conjunto. Até então, os medalhões haviam estado relegados a zonas pouco condignas, relativamente abandonados e alguns deles inidentificáveis (Frada e Botelho 1995).

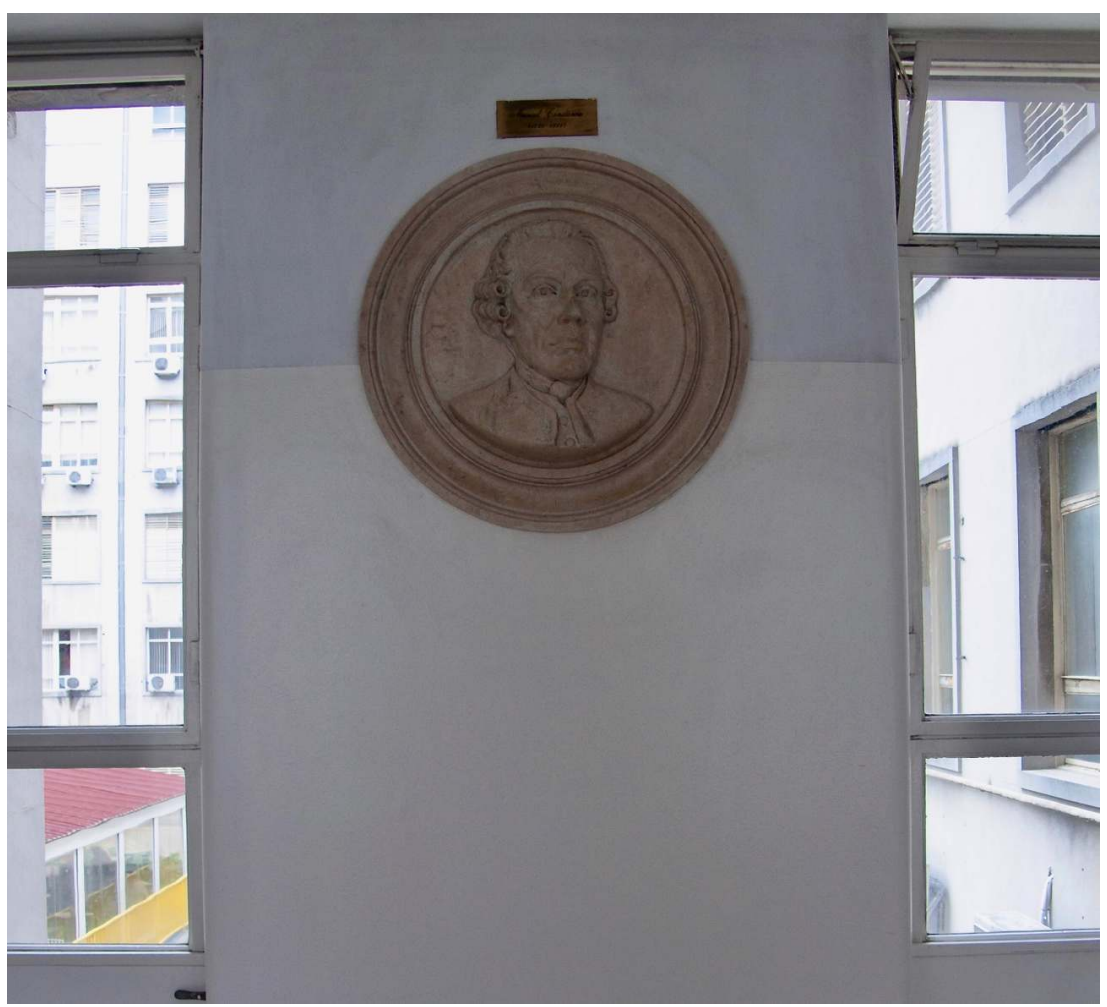

Fig. 2 - Medalhão retratando Manuel Constâncio, da autoria de Moreira Rato, 1906 Fotografia da autora, cortesia da Faculdade de Medicina da Universidade de Lisboa

No que concerne à escultura, a Faculdade dispõe de alguns bustos de professores, dois deles provenientes da Sala dos Passos Perdidos da Escola Médico-Cirúrgica (Botelho 1995). 0 busto representando José António de Arantes Pedroso (1822-1897), de traje académico e condecorado, foi encomendado pelo corpo docente da Escola Médico-Cirúrgica ainda durante o seu funcionamento no Hospital de S. José. O então falecido professor e diretor foi homenageado com uma obra do consagrado escultor Simões de Almeida (tio) (1844-1926), datada de 1897 e inaugurada em 1898, na altura colocada na Sala dos Atos (Serrano 1898). O segundo busto fixa José António Serrano (1852-1904), ilustre anatomista, também representado de traje académico. Foi feito por iniciativa dos estudantes e destinado já ao novo edifício da Escola Médico-Cirúrgica. Concebido por António Augusto da Costa Mota (tio) (1862-1930), data de 1905. Refira-se que Costa Mota (tio) executou igualmente a estátua de Sousa Martins (1907) que se encontra frente ao edifício da atual Faculdade de Ciências Médicas. Nas coleções da Faculdade de Medicina, em depósito no MUHNAC, encontra-se a recentemente (re)descoberta maqueta dessa obra (INV. MUHNAC-UL-DEP1516), até então desconhecida e um importante testemunho da evolução da obra final. Encontra-se assinada pelo autor e datada de 24.07.1901.

Do séc. XX, a Faculdade possui duas peças dignas de destaque. Do primeiro diretor do Instituto de Anatomia, Henrique de Vilhena (1879-1958), existe um busto em gesso (1922), assinado por Raul Xavier (1894-1964). O médico e historiador/crítico de arte Reynaldo dos Santos (1880-1970) foi fixado numa cabeça em bronze, algo estilizada, por Francisco Franco (1885-1955). ${ }^{24}$ 
Refira-se, também, a existência de um busto em bronze realizado pelo médico e artista Abel Salazar (1889-1946), que retrata de modo algo caricatural Augusto Celestino da Costa (1884-1956), professor da escola lisboeta com o qual, para além da relação profissional devido à Histologia, mantinha uma profunda amizade. Presume-se que tenha sido realizado na década de 1940, devido aos desejos que Salazar expressava a Celestino da Costa, em cartas, de executar um busto em barro (Coimbra 2006). Sabe-se que na primeira metade desta década, Salazar realizou um busto retratando Maurice Fréchet (1878-1973) para o Centro de Estudos Matemáticos (hoje integrado no acervo do MUHNAC ${ }^{25}$ ), que apresenta algumas semelhantes estilísticas ao busto de Celestino da Costa ${ }^{26}$.

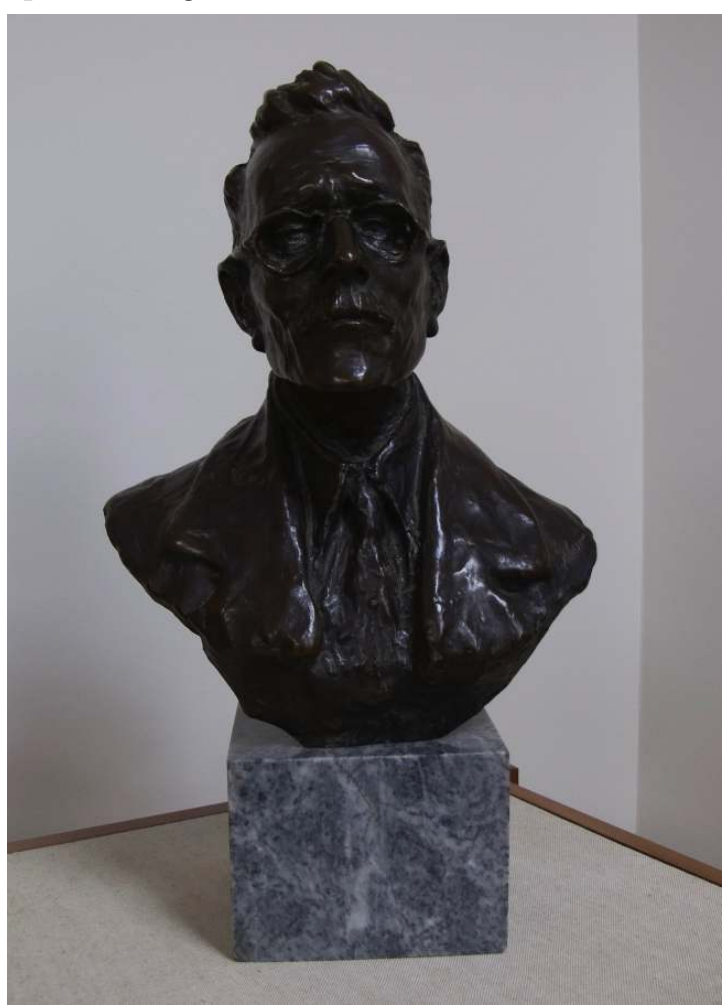

Fig. 3 - Busto representando Celestino da Costa, por Abel Salazar, sem data

Fotografia da autora, cortesia da Faculdade de Medicina da Universidade de Lisboa

Uma das figuras mais homenageadas da Faculdade, devido à concessão do prémio Nobel de Fisiologia ou Medicina em 1949, foi Egas Moniz (1874-1955). Especialista em Neurologia e Psiquiatria, Egas Moniz foi reconhecido pelo desenvolvimento da leucotomia pré-frontal e compreensão do seu valor terapêutico aplicado a determinadas psicoses. Egas Moniz recebe-nos na escadaria exterior que dá acesso à entrada da Faculdade, através de uma estátua de bronze colocada sobre um plinto em pedra, da autoria do escultor Euclides Vaz (1916-1991), de 1974, ano da comemoração do centenário do seu nascimento. Representado de pé, em escala ampliada, enverga traje de professor catedrático, com beca, capelo com rosáceas e barretina com borla que segura numa das mãos. Esta estátua veio substituir um busto que aí se encontrava, retratando igualmente Moniz, da autoria do escultor Pedro Anjos Teixeira (1908-1997), datado de 1956, que foi transferido para o Hospital Egas Moniz. ${ }^{27}$ 


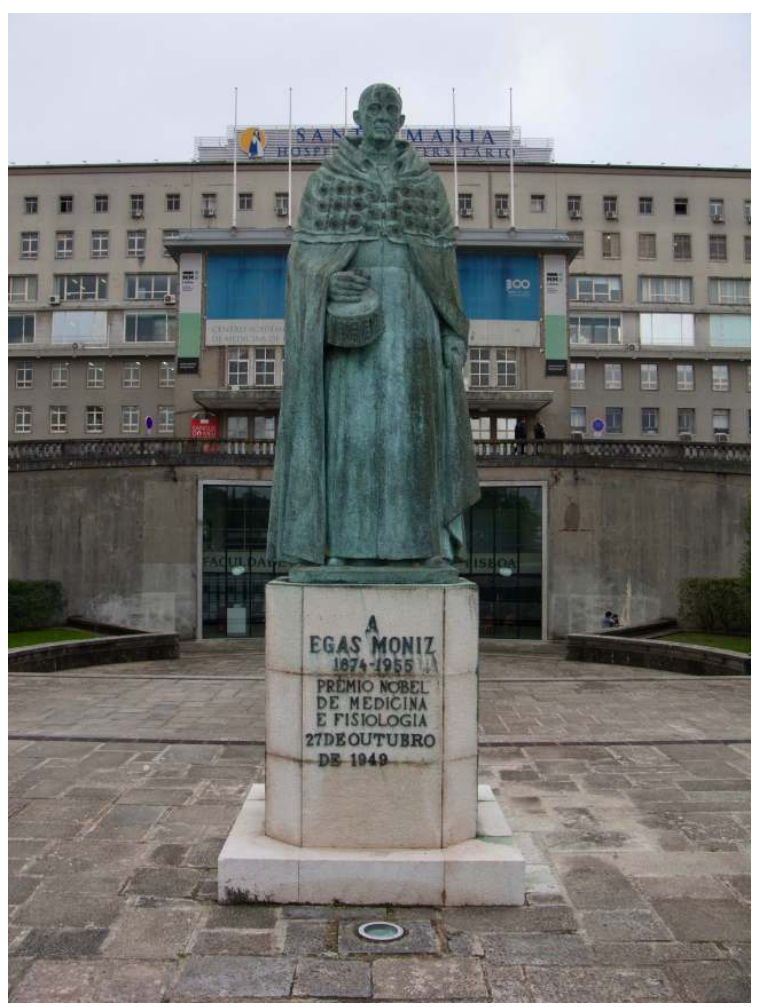

Fig. 4 - Estátua representando Egas Moniz, da autoria de Euclides Vaz, 1974

Fotografia da autora, cortesia da Faculdade de Medicina da Universidade de Lisboa Instituto de Anatomia. Foi executado pelo pintor barreirense Américo Marinho (1913-1997), que frequentou o curso de Anatomia Artística no ano letivo de 1929-1930, sob orientação do professor Henrique de Vilhena. Estima-se que tenha sido realizado nessa altura, nos inícios da década de $1930 .{ }^{31}$ A obra é um testemunho do decorrer das aulas de anatomia, com figuração de Vilhena e dos seus discípulos ${ }^{32}$, que atentam na sua explicação. Crê-se que se trata de uma obra não terminada, por não estar representado o 
cadáver sobre a mesa de dissecção em torno da qual se desenvolve a composição, e por não ter sido colorida.

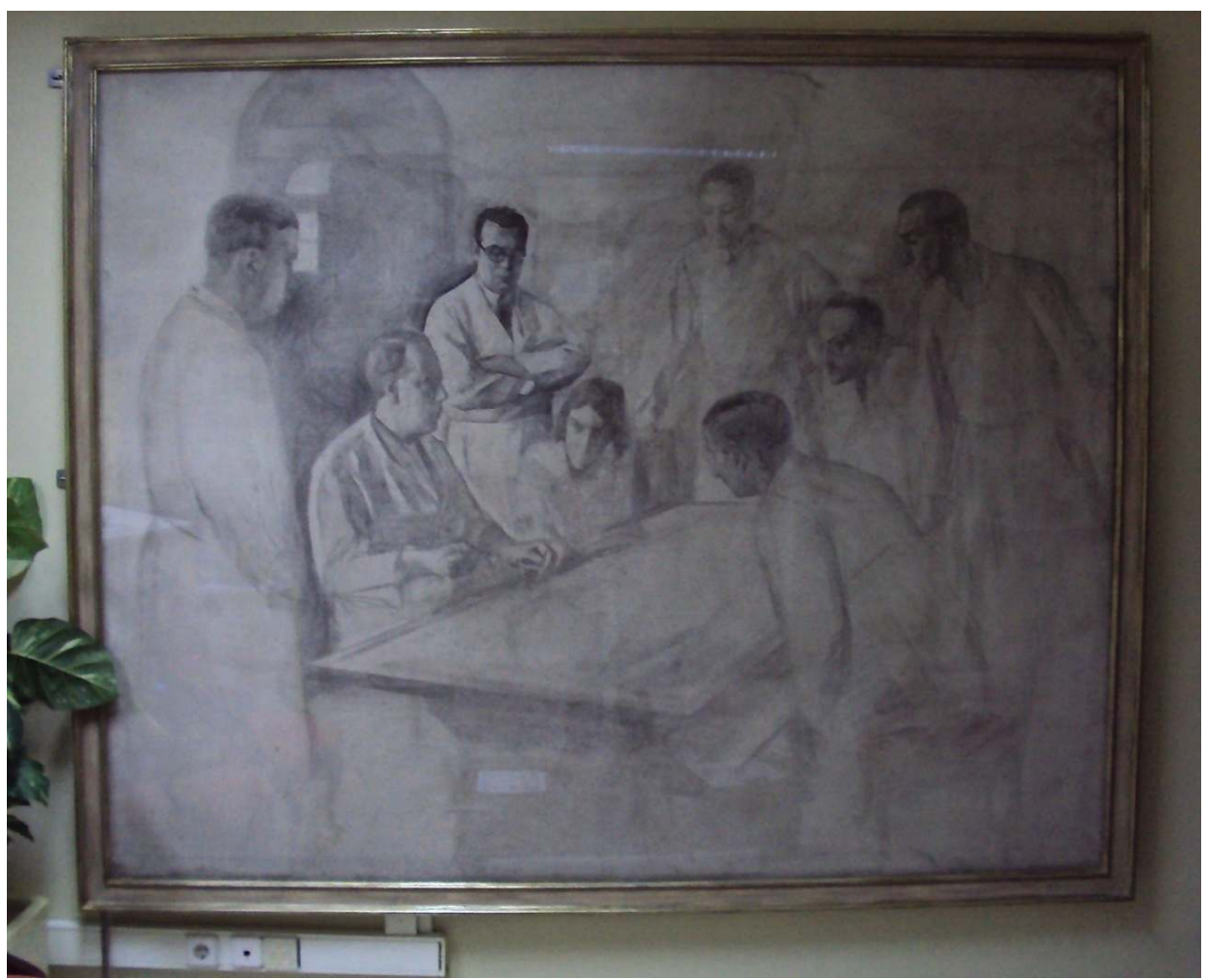

Fig. 5 - Desenho representando uma lição de anatomia em torno de Henrique de Vilhena, por Américo Marinho, sem data (c. 1930-31). Fotografado ainda na sua anterior localização, na biblioteca do Pólo das Ciências Morfológicas.

Fotografia de Catarina Teixeira, cortesia da Faculdade de Medicina da Universidade de Lisboa

No âmbito do curso de Anatomia Artística, que se dividiu entre o Instituto e a Escola de Belas-Artes (Vilhena 1947), refira-se o conjunto de cerca de 2000 desenhos, realizados entre 1905 e 1938. ${ }^{33}$ Abarcando diversas temáticas específicas, tais como ossos, músculos, corpo cadáver, entre outras, este núcleo - que já serviu de base a exposições ${ }^{34}$ - assume particular importância por incorporar obras de artistas entretanto consagrados no panorama nacional (ex. Dórdio Gomes, Estrela Faria, José Tagarro, Manuel Lapa, Thomaz de Melo, entre outros).

\section{Contributos para a valorização do património artístico da Faculdade de Medicina da Universidade de Lisboa}

O património artístico reunido pela Faculdade de Medicina apresenta-se heterogéneo em termos tipológicos, com enfoque em obras pictóricas e escultóricas que privilegiam o retrato. No entanto, possui um elemento aglutinador, que é transversal: a perpetuação da memória de figuras destacadas da instituição, e, por conseguinte, do seu contributo a nível da evolução da Medicina em Portugal. Cada uma das obras acima mencionadas comporta um caráter evocativo, que legitima a escola em termos de importância científica e de ancestralidade, tendo sido sobretudo realizadas como homenagem ou em contexto de comemoração. Por outro lado, a autoria das obras coube predominantemente 
a artistas reconhecidos no panorama artístico nacional, como José Malhoa, Columbano Bordalo Pinheiro ou Simões de Almeida, o que enaltece o valor deste legado artístico.

Na realidade, este conjunto assemelha-se a outros existentes na Universidade de Lisboa, como, por exemplo, nas Faculdade de Direito, de Letras e de Medicina Veterinária, ou nos Institutos Superior de Economia e Gestão e Superior de Agronomia, que integram galerias de pintura e bustos de antigos professores, fundadores, entre outros (Felismino 2016). Na esfera universitária tem-se assistido a uma crescente consciencialização da importância deste tipo de espólios e da sua preservação e valorização. No entanto, muitas vezes, esta tomada de consciência é feita de forma "interna", sem real visibilidade do grande público, dadas as dificuldades de possibilitar horários de acesso alargados pela inexistência de funcionários especialmente destacados para o efeito. Veja-se o exemplo da constituição de salas-museu no Instituto Superior de Ciências Sociais e Políticas, dedicadas à memória da instituição, e na Faculdade de Direito, com espólios, respetivamente, dos professores Marcelo Caetano e Paulo Cunha. No caso da Medicina, extravasando o universo das casasmuseu, como é o caso das dedicadas a Abel Salazar e a Egas Moniz, assinale-se, apenas a título de exemplo, o Centro de Memória Medicinal da Universidade de Federal de Minas Gerais, no Brasil, e o Museu de História da Medicina Maximano Lemos, na Faculdade de Medicina da Universidade do Porto. Ambos preservam a memória das instituições em que se inserem e da evolução da Medicina ao longo da História, através de instrumentos, documentação e bibliografia, incluindo também, embora em menor escala, algumas obras de arte de cariz evocativo. Fora do contexto universitário, importa mencionar a recente exposição 800 Anos de Saúde em Portugal (inaugurada em abril de 2017) organizada pelo Museu da Saúde/Instituto Nacional de Saúde Doutor Ricardo Jorge (INSA), que incorpora, a par de uma plêiade de instrumentos e equipamentos médicos de diversas cronologias, pinturas e elementos que se enquadram na temática memorial e evocativa.

Na própria Faculdade de Medicina da Universidade de Lisboa decorreram no passado várias iniciativas de valorização patrimonial. Nas décadas de 1980 e 1990, por ação do professor João Frada, realizaram-se exposições histórico-temáticas através do Gabinete de Museologia (Silva 2012). Recentemente, existiu um projeto de criação de um núcleo museológico, designado em 2005 como "Museu de Medicina", que, apesar de não ter recebido instalações físicas, realizou algumas exposições "fora de portas" apresentando parte do espólio histórico da instituição. Entre estas, merece destaque a exposição Passagens. 100 Peças para o Museu de Medicina (2005), realizada no Museu Nacional de Arte Antiga (cf. Alves 2005). Não obstante, o património artístico atrás identificado não viria a integrar o acervo desse museu, uma vez que não cessou, até hoje, de cumprir as suas funções cerimoniais e decorativas.

21 O primeiro passo para o reconhecimento mais alargado deste património foi dado aquando das comemorações do centenário da antiga Universidade de Lisboa, em 2011. Com base num levantamento sistemático (Pascoal, Teixeira e Lourenço 2012; Silva 2012) das coleções históricas, tanto científicas como artísticas, de toda a instituição, foi possível compreender o panorama patrimonial da Universidade e dá-lo a conhecer não só à comunidade académica como ao público mais generalizado, através de um volume publicado (Lourenço e Neto 2011) e pela realização de um conjunto de visitas guiadas. Por outro lado, determinadas obras encontravam-se já assinaladas no meio académico, nomeadamente as pinturas de Malhoa (Saldanha 2010) e de Columbano (Elias 2011), tendo outras sido pontualmente referidas em bibliografia diversa. 
22 Apesar da "classificação" do património sob a categoria de coleções no citado levantamento, um método aplicado como ferramenta de trabalho e de sistematização do avultado volume de informação, grande parte do espólio artístico da Faculdade de Medicina (e de outras escolas) não se encontra agrupado nesse sentido, estando antes circunscrito a nível de organização institucional (institutos, centros, salas nobres) e de localização física. Encontra-se disperso pelo edifício, sobretudo em zonas nobres e/ou restritas (é caso das pinturas de Columbano e dos medalhões de Moreira Rato) e em espaços de acesso semi-reservado, como institutos e bibliotecas - o que veda a sua fruição pela maior parte da comunidade estudantil, bem como de outro tipo de públicos. A sua gestão está, no entanto, a ser assegurada pela Faculdade, que centralizou esta tarefa sob alçada do Núcleo de Biblioteca e Informação. O facto de se encontrar identificado, e até ter sido já visitado por um público diversificado, contribui para o seu reconhecimento e para a sua proteção. Um exemplo semelhante sucede na Universidade de Sevilha, cujo património histórico-artístico se encontra identificado e disponibilizado online ${ }^{35}$, permanecendo fisicamente nas faculdades, institutos e demais localizações. Na realidade, nem todo o património é passível de ser musealizado, mesmo que detenha peso histórico, artístico e institucional como é o caso do núcleo aqui apresentado. A sua importância intrínseca torna-o num elemento de memória diário que importa preservar.

23 Esta tipologia patrimonial é transversal a diversas instituições públicas portuguesas, não apenas universidades, tendencialmente relegada para o já mencionado plano decorativo. Atentando nas metodologias de identificação e preservação expostas, o conhecimento e a investigação sobre estes núcleos poderia ser incrementada através da criação de redes entre os detentores, criando registos e inventários acessíveis, que permitam trocas de informação e, simultaneamente, compreender a importância da homenagem e da memória através do patrocínio de obras de arte. Importa, também, melhorar a acessibilidade do património universitário à comunidade académica, por forma a possibilitar a sua integração em estudos diversos, tanto de caráter geral como teses monográficas sobre os autores ou sobre os temas representados.

\section{Agradecimentos}

24 A autora agradece à Direção da Faculdade de Medicina da Universidade de Lisboa a autorização da publicação das imagens, e a Susana Henriques (Faculdade de Medicina da Universidade de Lisboa), Marta C. Lourenço e Catarina Teixeira (MUHNAC, Universidade de Lisboa). O presente artigo foi elaborado no âmbito da bolsa BGCT, financiada pela Fundação para a Ciência e a Tecnologia (SFRH/BGCT/51650/2011), no Museu Nacional de História Natural e da Ciência da Universidade de Lisboa (MUL/MUHNAC-ULisboa). 


\section{BIBLIOGRAFIA}

“A Velha e a Nova Escola Médica." 1906. Illustração Portugueza 2. série, n.ำ 4 (19 de março): 121-127. http://hemerotecadigital.cm-lisboa.pt/OBRAS/IlustracaoPort/1906/N4/N4_master/ N4.pdf

Afonso, Luís Urbano. 2013. “A Imagem do Saber: As Pinturas da Universidade de Lisboa em 1431.” In A Universidade Medieval em Lisboa: Séculos XIII-XVI, ed. Hermenegildo Fernandes, 305-315. Lisboa: Tinta da China.

Alves, Manuel Valente, ed. 2005. Passagens: 100 Peças para o Museu de Medicina. Lisboa: Museu de Medicina.

Arquivo Histórico da Secretaria-Geral da Educação e Ciência. PT/MESG/AAC/JNE/G-A/01801 AHME, proc. 096, cx. 292: Restauro de pinturas da Faculdade de Medicina de Lisboa.

Bernardo, José Viriato. 2014. “A Coleção de Escultura da Faculdade de Belas-Artes: A Formação do Gosto e o Ensino do Desenho.” Dissertação de doutoramento em Belas-Artes (Desenho), Universidade de Lisboa.

Botelho, Luiz da Silveira. 1995. “A Escola Médica do Campo Santana.” Ata Médica Portuguesa 8 (4): 259-264.

Centro de Documentação do Atelier-Museu António Duarte, Centro de Artes das Caldas da Rainha. AMAD/MED/XVI-1: Medalhão do Professor Egas Moniz, Praça Egas Moniz, Santiago do Chile 1958.

Cid, Francisco Maria N. P. de Salter. 2013. “Arte Sacra na Escultura de Domingos Soares Branco.” Dissertação de mestrado em Escultura Pública, Universidade de Lisboa.

CML/DPC/DM. 1998. O Atelier de Leopoldo de Almeida. Lisboa: Câmara Municipal de Lisboa/ Departamento de Património Cultural/Divisão de Museus (CML/DPC/DM).

Coimbra, António, org. 2006. 96 Cartas de Abel Salazar a Celestino da Costa. Lisboa: Gradiva.

Costa, Jaime Celestino da. 2000. A Geração Médica de 1911. Origem, Realização e Destino. Lisboa: Faculdade de Medicina da Universidade de Lisboa.

Elias, Margarida. 2011. “Columbano no seu Tempo (1857-1929).” Dissertação de doutoramento em História da Arte Contemporânea (Séculos XX-XX), Universidade Nova de Lisboa.

Felismino, David. 2016. “Memória da Universidade." In A Universidade de Lisboa. Museus, Coleções e Património, ed. Marta C. Lourenço, 161-207. Lisboa: Universidade de Lisboa.

Frada, João, e Madalena Botelho. 1995. “Os Medalhões da Faculdade de Medicina de Lisboa." Ata Médica Portuguesa 8 (6): 385-391.

Freitas, Maria Helena de. 1999. “A Escola Médica de Columbano: Quatro Retratos.” In 1911-1999: O Ensino Médico em Lisboa no Início do Século. Sete Artistas Contemporâneos evocam a Geração de 1911, dir. Manuel Valente Alves, 167-169. Lisboa: Fundação Calouste Gulbenkian.

Lourenço, Marta C. 2005. "Between Two Worlds: The Distinct Nature and Contemporary Significance of University Museums and Collections in Europe." Thèse de doctorat, Histoire des Techniques, Muséologie, Conservatoire Nationale des Arts et Metiers, Paris. 
Lourenço, Marta C., e Maria João Neto, coords. 2011. Património da Universidade de Lisboa. Ciência e Arte. Lisboa: Tinta da China.

Mega, Rita. 2012. “Vida e Obra do Escultor Leopoldo de Almeida (1898-1975).” Dissertação de doutoramento em Belas-Artes (Ciências da Arte), Universidade de Lisboa.

MOP/CANIU. 1959. Faculdade de Medicina e Hospital de São João. Porto: [s.n.].

Mora, Luiz Damas. 2009. “O Dr. Manoel Constâncio (1726-1817) e a Reestruturação do Ensino Cirúrgico em Portugal.” Revista Portuguesa de Cirurgia 8: 87-94.

Oliveira, Victor. 2013. “Retrato de Manuel Constâncio.” Ata Médica Portuguesa 26 (5): 623-625.

Pascoal, Ana Mehnert, Catarina Teixeira, e Marta C. Lourenço. 2012. “The University of Lisbon's Cultural Heritage Survey (2010-2011)." UMACJ 5: 101-110.

Pascoal, Ana Mehnert. 2012. A Cidade do Saber. O Património Artístico Integrado nos Edifícios de Pardal Monteiro para a Cidade Universitária de Lisboa (1934-1961). Lisboa: Universidade de Lisboa.

Pascoal, Ana Mehnert. 2017. “A Construção dos Hospitais Escolares de Lisboa e Porto.” In Médicos e Sociedade. Para uma História da Medicina em Portugal no Século XX, coord. A. J. Barros Veloso, 366-380. Lisboa: By the Book.

Pina, Madalena Esperança. 2007. “Traços da Medicina na Azulejaria de Lisboa.” Dissertação de doutoramento no ramo de Ciências da Vida, na especialidade de História das Ciências da Saúde, Universidade Nova de Lisboa.

Pina, Madalena Esperança. 2010. “As Faculdades de Medicina na I República.” In Corpo. Estado, Medicina e Sociedade no Tempo da Primeira República, ed. R. Garnel, 30-37. Lisboa: Imprensa Nacional - Casa da Moeda.

Sacadura, S. da. Costa, e J. T. Montalvão Machado. 1965. Andanças do Ensino Médico na Capital: Do Hospital Real de Todos-os-Santos ao Hospital de Santa Maria. Porto: Tipografia Sequeira.

Saldanha, Nuno. 2010. José Malhoa: Tradição e Modernidade. Lisboa: Scribe.

Serrano, José António. 1898. O Professor Arantes: Discurso Lido em 19 de janeiro de 1898 na Sessão Inaugural do Busto de Bronze Ereto a Expensas. Lisboa: Tipografia de Libânio da Silva.

Serrão, Vítor. 2009. “A Universidade de Coimbra e as Artes. Uma dimensão do Sublime.” In A Universidade de Coimbra. O Tangível e o Intangível, coord. José Francisco de Faria Costa, e Maria Helena da Cruz Coelho, 11-62. Coimbra: Imprensa da Universidade de Coimbra.

Silva, Ana Catarina Teixeira da. 2012. "Património Cultural da Universidade de Lisboa: Levantamento e Contributo para a sua Valorização.” Trabalho de projeto de mestrado em Museologia, Universidade Nova de Lisboa.

Turner, Paul Venable. 1984. Campus: An American Planning Tradition. Cambridge: The MIT Press. Vilhena, Henrique de. 1947. "Trinta e Três Anos no Ensino da Anatomia Artística." Arquivos de Anatomia e Antropologia, vol. XXIV: 524-589.

\section{NOTAS}

1. "Cast Collection of Ancient Sculptures": http://university-museums-and-collections.net/berlin/ cast-collection-of-ancient-sculptures (consultado junho 20, 2017).

2. "Scientific Iconographies Collection": http://university-museums-and-collections.net/ montpellier/scientific-iconographies-collection (consultado junho 20, 2017). 
3. Inclui diversas tipologias de desenho, como topografia, geometria descritiva, máquinas, etc. Esta coleção integra, ainda, ilustrações anotadas de fauna, flora e antropologia realizadas no âmbito das expedições científicas setecentistas encetadas pela Coroa portuguesa.

4. Inventário pesquisável através da página oficial do MISEP: https://www2.isep.ipp.pt/museu/ index.php?page=base-de-dados (consultado janeiro 20, 2018).

5. "Gustavianum. Portraits in the University main Building": http://www.gustavianum.uu.se/artcollection/collections/portraits-in-the-university-main-building/ (consultado junho 14, 2017).

6. "Patrimonio Historico-artistico Universidad de Sevilla: Conjuntos, Colleciones y Series": http:// www.patrimonioartistico.us.es/lista_completa.jsp?campo=grupo\&page=con (consultado junho 14, 2017).

7. "The Arkadenhof (arcaded courtyard) in the main Building of the University of Vienna": http:// geschichte.univie.ac.at/en/articles/arkadenhof-arcaded-courtyard-main-building-universityvienna (consultado junho 14, 2017).

8. A Sala dos Capelos, originalmente Sala do Trono do Paço Real, foi adaptada à função que ainda hoje possui em 1544; a sua configuração, mantida de forma relativamente inalterada, deriva de uma remodelação efetuada no séc. XVII. As pinturas foram incumbidas a Carlos Falch (1656) (Serrão 2009).

9. Desde 1973, funciona no edifício a Faculdade de Ciências Médicas da Universidade Nova de Lisboa.

10. Embora não seja o foco deste artigo, refira-se que nesta época se desenvolvia em paralelo, nos Estados Unidos, o planeamento do campus universitário, na senda dos colleges ingleses, tornandose numa tipologia arquitetónica própria e indissociável do panorama universitário do país (Turner 1984).

11. A Faculdade e o Hospital possuem tutelas e administrações distintas. Embora no projeto inicial se tenha planeado a separação de serviços e áreas, a transição entre cada uma é fluida e dilui-se no espaço, uma vez que as barreiras físicas são praticamente inexistentes.

12. No espaço do Hospital, apenas na capela se denota alguma preocupação em incorporar elementos artísticos de cariz religioso dada a sua natureza e função; estes, somente vieram a ser integrados mais de uma década após o término da construção do edifício. Trata-se de três peças escultóricas da autoria de Domingos Soares Branco (1925-2013): uma estátua de São João Batista em bronze (1956) sobre a pia batismal; uma escultura de Nossa Senhora da Saúde em barro passado a gesso (1960); e uma porta em bronze com baixo-relevo integrada no sacrário de mármore (1964) (Cid 2013).

13. Refiram-se, a título de exemplo, os seguintes: uma estátua de Eduardo Tavares representando Ricardo Jorge, os painéis cerâmicos de Júlio Resende na entrada, e uma tapeçaria mural de Guilherme Camarinha para a Sala do Conselho (MOP/CANIU 1959).

14. Além das obras de arte móveis, a transferência incluiu equipamentos e instrumentos diversos de apoio ao ensino e à investigação. Um conjunto considerável (c. 3000 objetos) está presentemente em depósito no MUHNAC. O estudo da sua proveniência está ainda por fazer, embora, em alguns casos, seja possível identificar a sua origem através de etiquetas antigas.

15. A informação sobre o património aqui indicado foi recolhida, primeiramente, no âmbito do Levantamento do Património Cultural da Universidade de Lisboa, realizado entre 2010 e 2011 no contexto das comemorações do centenário da antiga Universidade de Lisboa. Os seus resultados foram publicados na obra Património da Universidade de Lisboa. Ciência e Arte (Lourenço e Neto 2011). A confirmação da informação e localização do património foi realizada in situ em 2017, com o auxílio de Susana Henriques da Faculdade de Medicina da Universidade de Lisboa.

16. Por ocasião do XV Congresso Internacional de Medicina; porém, as aulas só se iniciaram em 1911 (Botelho 1995; Pina 2010).

17. Para uma perspetiva dos interiores à data da inauguração, veja-se o artigo "A Velha e a Nova Escola Médica" (1906) publicado na revista Illustração Portugueza. 
18. Encontram-se retratados os seguintes: Miguel Bombarda (1851-1910); Silva Amado (1840-925); Curry Cabral (1844-1920); Bettencourt Pitta (1826-1907) e J. Ferraz de Macedo (1838-1907) (tela datada de 1906, INV. MUHNAC-UL14900); Eduardo Motta (1837-1912); May Figueira (1829-1913); Sabino Coelho (1853-1938); Ricardo Jorge (1858-1939) e Oliveira Feijão (1850-1918) (tela de 1907, INV. MUHNAC-UL14901); Augusto Vasconcelos (1867-1951); J. Salazar de Sousa (1871-1940); José Gentil (1870-1938) e Francisco Gentil (1878-1964) (obra de 1907, INV. MUHNAC-UL14902); C. Bello Morais (1868-1933); Moreira Júnior (1866-1954); Carlos Tavares (1837-1913); Alfredo da Costa (1859-1910); Custódio Cabeça (1866-1937) e Bettencourt Raposo (1853-1937) (tela de 1906, INV. MUHNAC-UL14903).

19. Arquivo Histórico da Secretaria-Geral da Educação e Ciência. PT/MESG/AAC/JNE/G-A/01801 AHME, proc. 096, cx. 292: Restauro de pinturas da Faculdade de Medicina de Lisboa.

20. Cinco retratos possuem a inscrição "Escola", nomeadamente: Manoel Bento de Sousa (1835-1899); João Pedro Barral (1805-1862); José Eduardo de Magalhães Coutinho (1815-1895); Francisco António Barral (1801-1971); e Thomaz de Carvalho (1819-1897). Acrescem telas representando os professores João Mendes Arnaut (1816-1896), Joaquim Pedro Abranches Bizarro (1805-1860), António José de Lima Leitão (1787-1856), e o cirurgião António Joaquim Farto (c. 1783-1856).

21. Esta quinta, em Sentieiras, foi mandada construir por Manuel Constâncio (Mora 2009).

22. Foram, inclusivamente, transferidos alguns elementos de cantaria do edifício da Escola Médica-Cirúrgica, hoje colocados em destaque no átrio de entrada do edifício Egas Moniz.

23. Os representados foram: Manuel Constâncio (1725-1817); António de Monravá y Roca (1688-1753); Bernardo Santucci (1701-1754); Afonso Rodrigues de Guevara (?-1587); Pedro Dufau (1717-1806); António Ferreira (1616-1679); Joaquim José de Sant'ana (?-1814); Bernardino António Gomes (1806-1877); José Lourenço da Luz (1800-1882); António Gomes Lourenço (?-1800); António de Almeida (?-1822); e António da Cruz (?-1626).

24. Mencione-se que o Museu Henrique e Francisco Franco (Funchal) possui duas peças idênticas: um estudo em gesso patinado e uma peça em bronze, assinada e com marca de fundidor, à semelhança da peça existente na Faculdade de Medicina.

25. Cf. INV. MUHNAC-UL3494.

26. No fundo de Abel Salazar, disponibilizado online através da Fundação Mário Soares, encontrase uma fotografia do busto da Faculdade de Medicina, incorretamente designado como representando Maurice Fréchet: Escultura de Abel Salazar. http://www.fmsoares.pt/aeb_online/ abel_salazar/visualizador.php?nome_da_pasta=06354.000.085\&bd=Fotografias (consultado junho 16, 2017).

27. "Egas Moniz - bronze, busto": http://www.cm-lisboa.pt/equipamentos/equipamento/info/ egas-moniz-bronze-busto (consultado junho 16, 2017).

28. O CEEM foi criado em 1950, originalmente localizado em instalações anexas ao Hospital Júlio de Matos; em 1957, iniciou uma nova fase da sua existência.

29. O estudo para esta peça, realizado em gesso, encontra-se no Museu de Lisboa (n.. de inventário ESC 175, veja-se: CML/DPC/DM 1998). Existe, no Centro de Artes das Caldas da Rainha, um exemplar em gesso patinado (n.. inv. LA-01901) (cf. Mega 2012, ficha n.․396).

30. Documentação à guarda do Centro de Documentação do Atelier-Museu António Duarte, Centro de Artes das Caldas da Rainha, referência: AMAD/MED/XVI-1 Medalhão do Professor Egas Moniz, Praça Egas Moniz, Santiago do Chile - 1958.

31. Encontram-se desenhos no espólio à guarda do Instituto de Anatomia que constituem estudos individualizados de algumas das figuras representadas, estando um deles datado de "1930 ou 31"; a maioria foi igualmente realizada a carvão, embora exista uma pequena tela pintada com a composição total apenas esquematicamente representada, talvez demonstrando o intento que Marinho pretendia para a obra final. Um outro estudo a carvão apresenta um cadáver sobre a mesa. 
32. Fernando de Almeida (1903-1979); Corino de Andrade (1906-2005); Cesina Bermudes (1908-2001); Pedro Mayer Garção (1905-?); Victor Fontes (1893-1979); Barbosa Sueiro (1894-1974); e João Cid dos Santos (1907-1975).

33. $O$ conjunto de desenhos encontra-se organizado tematicamente.

34. Refira-se, a título de exemplo, a exposição Gabinete de Anatomia: Arpad, Vieira e os Desenhos Anatómicos do Museu de Medicina, que esteve patente no Museu da Fundação Arpad Szenes-Vieira da Silva, em Lisboa, de 6 maio a 25 setembro de 2011.

35. "Patrimonio historico-artistico Universidad de Sevilla": http://www.patrimonioartistico.us.es/ index.jsp (consultado junho 16, 2017).

\section{RESUMOS}

O património artístico da Faculdade de Medicina da Universidade de Lisboa, proveniente maioritariamente da instituição que a antecedeu, a Escola Médico-Cirúrgica de Lisboa (1836-1911), é constituído por pinturas e esculturas da autoria de vultos do panorama artístico nacional como José Malhoa, Columbano Bordalo Pinheiro ou Simões de Almeida. Neste artigo examinamos este património, atendendo ao seu caráter de memória e ao enquadramento numa faculdade de cariz científico. Apresenta-se uma breve reflexão acerca da pertinência desta tipologia de património universitário, abordando formas de gestão, preservação e divulgação, atendendo a exemplos nacionais e internacionais.

The artistic heritage of the Faculty of Medicine of the University of Lisbon has its origins in the Escola Médico-Cirúrgica de Lisboa (1836-1911). It includes paintings and sculptures, mostly authored by nationally renowned artists such as José Malhoa, Columbano Bordalo Pinheiro or Simões de Almeida. The present article intends to characterize and examine this heritage through the angle of institutional history and memory in the context of a scientific institution. A brief analysis on the importance of this typology of university heritage is followed by the discussion of management, preservation and dissemination issues, illustrated with national and international examples.

ÍNDICE

Keywords: artistic heritage, Faculty of Medicine of the University of Lisbon, institutional memory, university collections

Palavras-chave: património artístico, Faculdade de Medicina da Universidade de Lisboa, Escola Médico-Cirúrgica de Lisboa, memória institucional, coleções universitárias

\section{AUTOR}

\section{ANA MEHNERT PASCOAL}

Mestre em Arte, Património e Teoria do Restauro (2010) e licenciada em História da Arte (2008) pela Faculdade de Letras da Universidade de Lisboa. Presentemente, é bolseira de investigação do ARTIS (Instituto de História da Arte, Faculdade de Letras da Universidade de Lisboa) no âmbito do 
projeto CuCa_RE: Cure and Care_the Rehabilitation (PTDC/ATPAQI/2577/2014). Tem desenvolvido investigação sobre património arquitetónico e artístico, particularmente de cariz universitário. Instituto de História da Arte (ARTIS), Faculdade de Letras da Universidade de Lisboa, Alameda da Universidade 1600-214 Lisboa, Portugal, anapascoal@campus.ul.pt 